\title{
An innovative construction technique for curved structures
}

\author{
Alessio Cascardi 1,*, Francesco Micelli ${ }^{2}$ and Maria Antonietta Aiello ${ }^{12}$ \\ 1 ITC - Construction Technologies Institute, CNR - Italian National Research, Bari - 70124 (Italy); \\ alessio.cascardi@itc.cnr.it \\ 2 Department of Innovation Engineering, University of Salento, Lecce - 73100 (Italy)2; \\ francesco.micelli@unisalento.it \\ * Correspondence: alessio.cascardi@itc.cnr.it
}

\begin{abstract}
The masonry building Heritage is appreciated for its aesthetic and historical value all around the world. The widespread presence of curved elements, such as arch, vault and dome express the relevant constructive abilities in the different historical epochs. These curved elements are characterized by architectural beauty, structural strength (especially against the gravity loads), thermal comfort and fire resistance. On the other hand, curved structures required scaffolding in order to be erected. The design, the construction and the dismantling of the scaffolds is typically time-consuming and expensive. In addition, the on-site working risk is related to time-interferences (e.g. in manpower working, at the same time, over and under scaffold). This technology dates back to the Era of the Roman Empire and it is currently still used, despite its limitations and disadvantages.

In the present paper, an innovative technique (recently patented), aiming for the construction of a curved structural member without scaffolds, is proposed and illustrated. It consists in a Hinged Lifting Arch (HLA), using FRP (Fiber Reinforced Polymer) bonded strips. In details, a series of blocks are cut following an arch geometry and then aligned on the ground-floor in order to bond a composite on their top surface. Moreover, the impregnation of the polymeric adhesive is not allowed at the extremities of each block. The fiber sheet is applied continuously along the entire extrados. In this sense, hinges are introduced, in fact, the FRP-connected blocks are able to easily rotate, in the opposite direction, around the contact ends (i.e. hinge). Finally, the middle block is lifted-up and the arch takes the desiderated shape. In the first experimental demonstration, the natural calcareous stone was used, even if the proposed technique is totally material-independent. Moreover, an analytical model is proposed and discussed for designing the proper aspect ratio of the blocks in order to ensure the full mutual contact when the HLA is totally lifted up. The advantages of the proposed technique are related to the absence of scaffolds and improved seismic strength against horizontal loads thanks to the presence of the FRP, which limits the occurrence of hinges at the extrados.
\end{abstract}

Keywords: arch, FRP, masonry, design-oriented model, patent.

\section{Introduction}

The masonry arch was the typical construction technique for roofing systems before the use of iron and other modern materials. It was used in the past, especially in the Mediterranean areas, due to its architectural value and its static carrying capacity, in addition to the thermal inertia and fire resistance, [1-3]. Despite these significant advantages, new curved members are currently less and less frequent due to the disadvantages mainly associated with the construction technology, if compared to modern materials. In fact, the construction of curved members necessarily requires the built of scaffolding; namely "centina". Large structures, such as vaults and domes, require huge and complex centina (steel or timber made). As a consequence, the time and cost consuming, related to manpower and design, is relevant. Moreover, on-site risk related to "material falling from above" or "man falling into the void" have to be carefully considered. A crucial case is the construction of the 
bridge arch above rivers or cliffs. Finally, seismic vulnerability is another limit of curved masonry structures, [4,5].

The present paper aims to report on a new construction technique for curved members, alternative to the centina method. The proposal was recently patented; [6]. In particular, a design methodology and a prototype construction are both reported in the next sections in order to demonstrate the validity of the technology. The design specifically refers to the geometrical aspect of the structural element (e.g. curvature, thickness, width, span/height ratio); while mechanical behavior can be predicted by available theoretical models through trust-line method, $[7,8]$.

\section{Proposed technology}

A masonry curved member is generally composed of a group of stone block, side-by-side placed, on a wooden shape-imposed support (i.e. centina), which is removed after the member geometry is completed. In order to properly meet the shape of the centina, mortar-based joints are generally modelled in between of two adjacent stone blocks. Alternatively, the procedure illustrated in Figure 1 (related to the case of an arch) can be executed: the blocks are aligned on the floor; a tensile-resistant material is bonded on the blocks and finally the middle block is lifted up. The use of Fiber Reinforced Polymer (FRP) is adequate for joining the blocks; $[9,10]$. In order to facilitate the relative rotation between two adjacent blocks, the polymeric matrix is applied discontinuously: the area near the contact between blocks is resin-free in order to develop a hinge. At this scope, a butyl tape is applied on the contact line before the resin wet lay-up and then removed when the FRP is placed on the extrados. The key-block (i.e. the central block) lifting produces the sliding of the other blocks on the base support. In order to allow, as much possible, the horizontal movement, a Mylar ${ }^{\mathrm{TM}}$ sheet is interposed in between for limiting the friction. So, the proposal consists in a Hinged Lifting Arch (HLA). The lift should be carefully performed in correspondence of the middle-line of the key-stone for avoiding extreme in-plane rotation of the suspended body that can imply undesired overturning and consequent fall down of the HLA. In such way, the construction is time and cost saving, and FRP-strengthened.

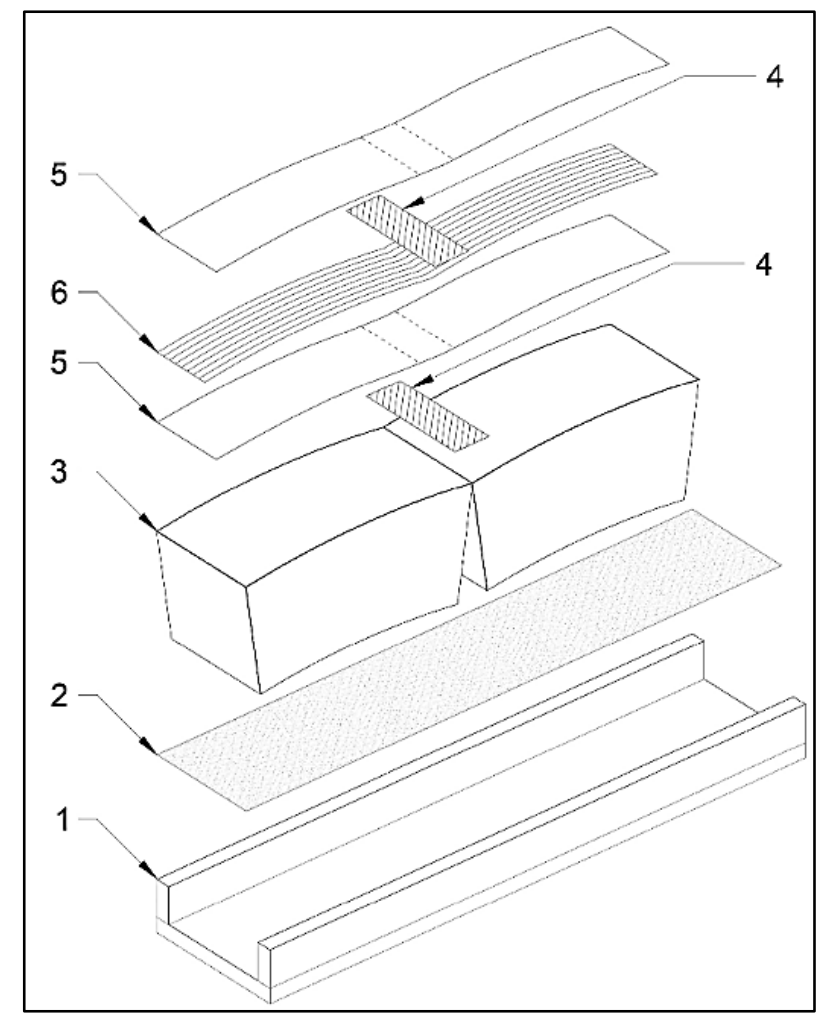




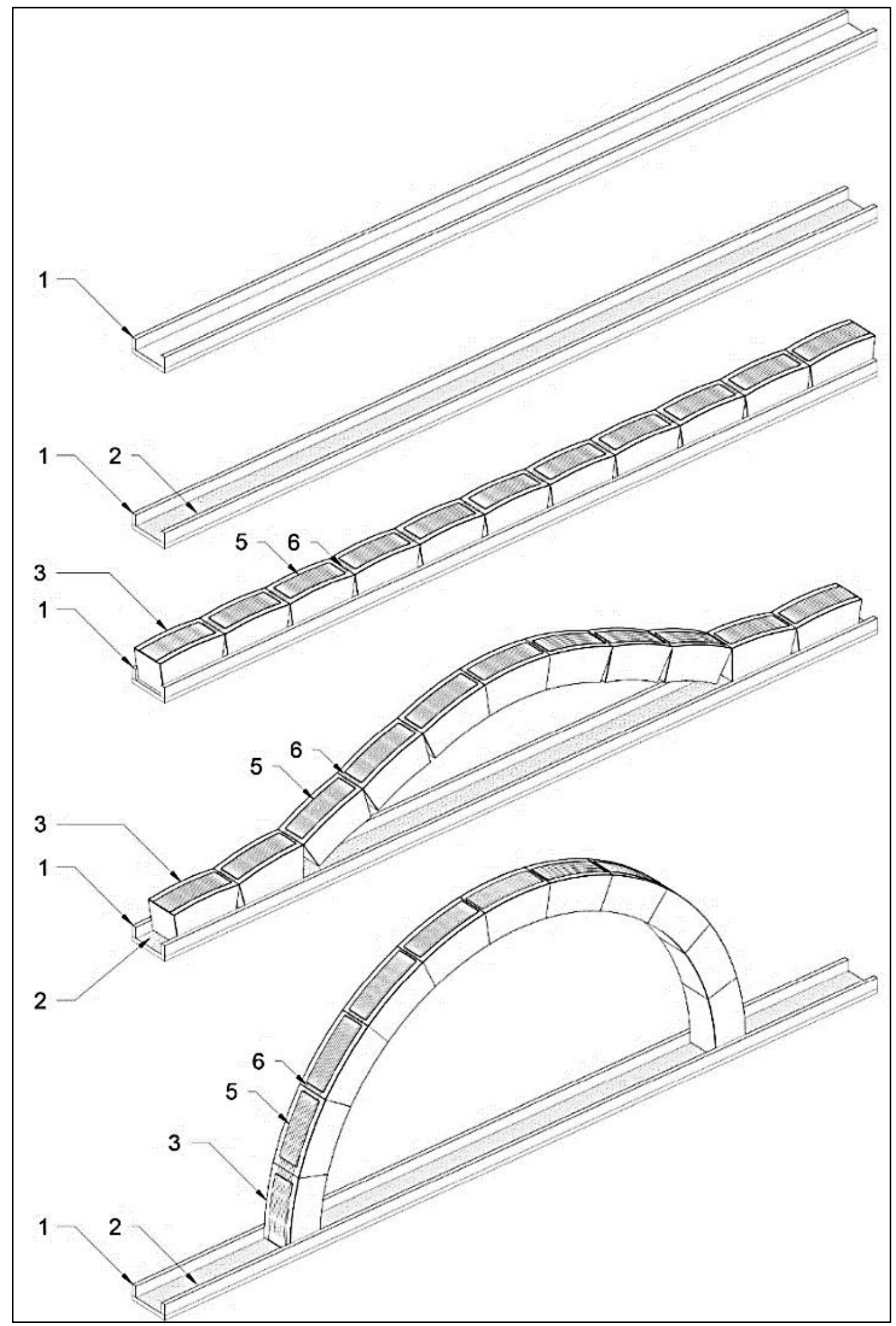

Figure 1. Description of the proposed technology, hinge achievement (top) and construction progress (bottom): 1 - base support constrains; 2 - Mylar ${ }^{\mathrm{TM}} ; 3$ - arch block; 4 - butyl tape; 5 - epoxy-based matrix; 6 - fiber sheet. 
The HLA is governed by the equilibrium of the suspended bodies (see Figure 2). When a body is suspended with respect to a point $\mathbf{P}$, it tends to reach equilibrium by vertical alignment respect to the centroid $\mathrm{G}$. The relative position of $\mathrm{P}$ and $\mathrm{G}$ affects the status of the suspended body. In particular, in case of $\mathrm{P}$ over $\mathrm{G}$ the equilibrium is stable (Figure $2 \mathrm{a}$ ); in case of $\mathrm{G}$ over $\mathrm{P}$ the equilibrium is unstable (Figure $2 \mathrm{~b}$ ) and in case of $\mathrm{P}$ coincident with $\mathrm{G}$ the equilibrium is indifferent (Figure $2 \mathrm{c}$ ). Based on this theory, a block of the HLA finds a stable position in the space when its Centre of Instant Rotation (C.I.R.) is vertically aligned with the centroid according to Figure 3. Consequently, the bottom surface is inclined with respect to the horizontal of an angle, herein named Gravity Rotation Angle (GRA).

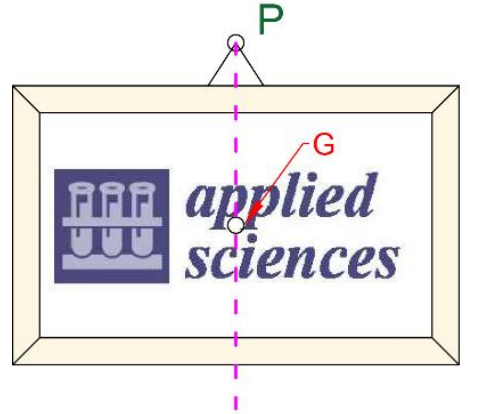

a)

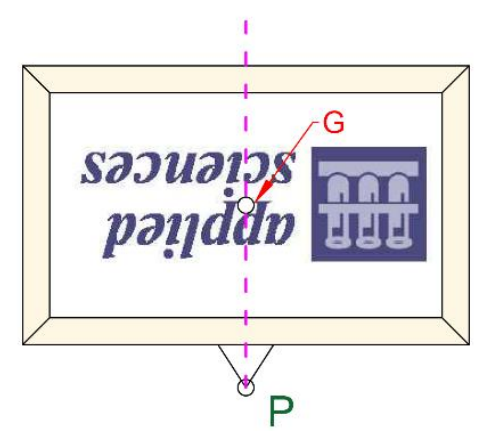

b)

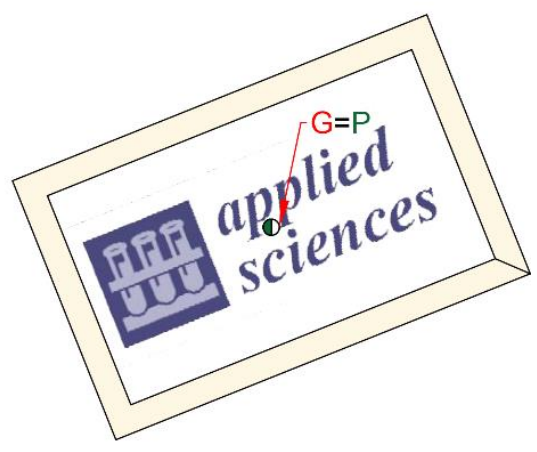

c)

Figure 2. Suspended bodies: a) stable equilibrium, b) unstable equilibrium and c) indifferent equilibrium.
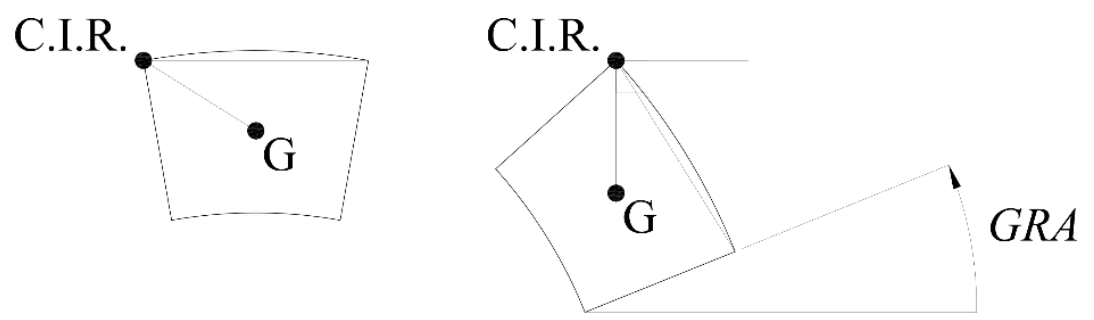

Figure 3. A block of the HLA: base supported (left) and suspended with respect to the CIR, in a stable equilibrium (right).

\section{Design procedure}

This section is aimed to report a design-oriented model for the geometry of the HLA. In the absence of external force, a suspended body reaches a stable equilibrium depending on his gravity force. The rotation can be defined by the GRA, which is strongly correlated with the aspect ratio (length over width) of the body itself. For this reason, the relationship between GRA and $l \mathrm{~m} / \mathrm{s}$ was investigated and results are reported in Figure 4, where $l_{m}$ is the length of the middle line of each block and $\mathrm{s}$ is the width of the block. It is demonstrable that when an annular section segment is lifted up, as illustrated in Figure 4, the GRA is the same as that one reached by a rectangle having as sides the segment connecting CIR and the intercept with the horizontal (passing through G) $-\boldsymbol{b}-$ and the segment connecting this point with the intercept of the horizontal axis with the normal line to the face of the free side of the annular section segment itself, passing through CIR $-\boldsymbol{h}$. 


$$
\begin{aligned}
& \text { GRA }=\alpha \\
& \alpha+\beta=90^{\circ} \\
& \gamma+\beta=90^{\circ}
\end{aligned} \longrightarrow \begin{aligned}
& \text { GRA }=\gamma \\
& \gamma=\operatorname{arctg}(\mathrm{h} / \mathrm{b})
\end{aligned}
$$
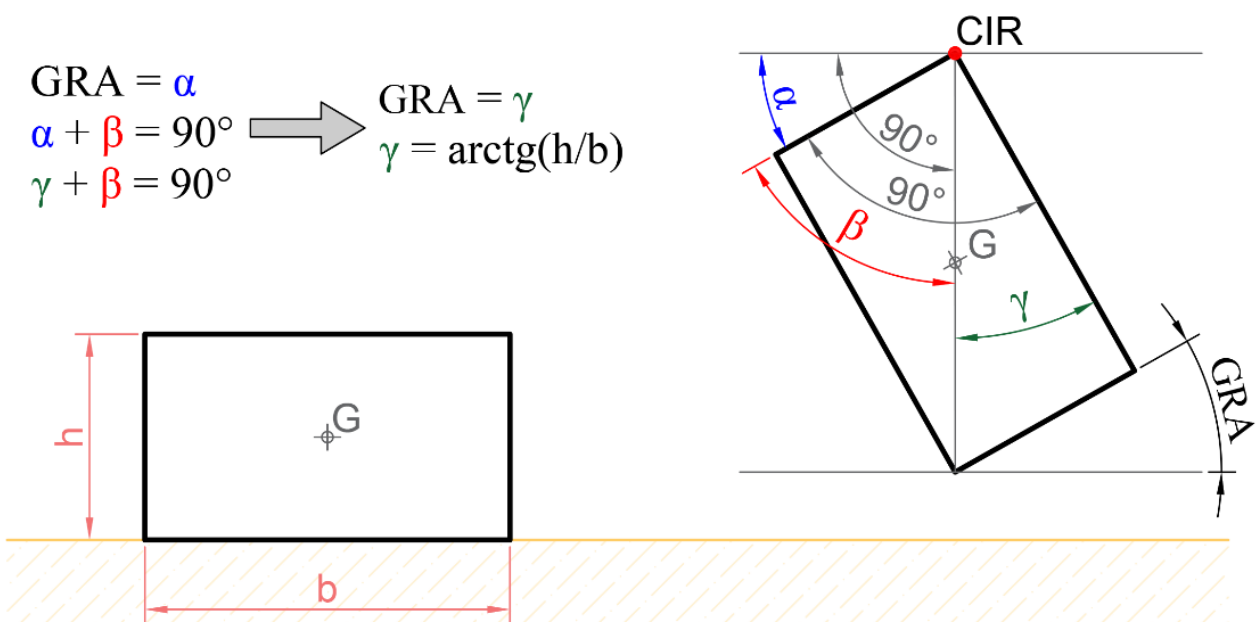

$$
\mathrm{GRA}=\alpha
$$

$\alpha=\operatorname{arctg}(\mathrm{h} / \mathrm{b})$
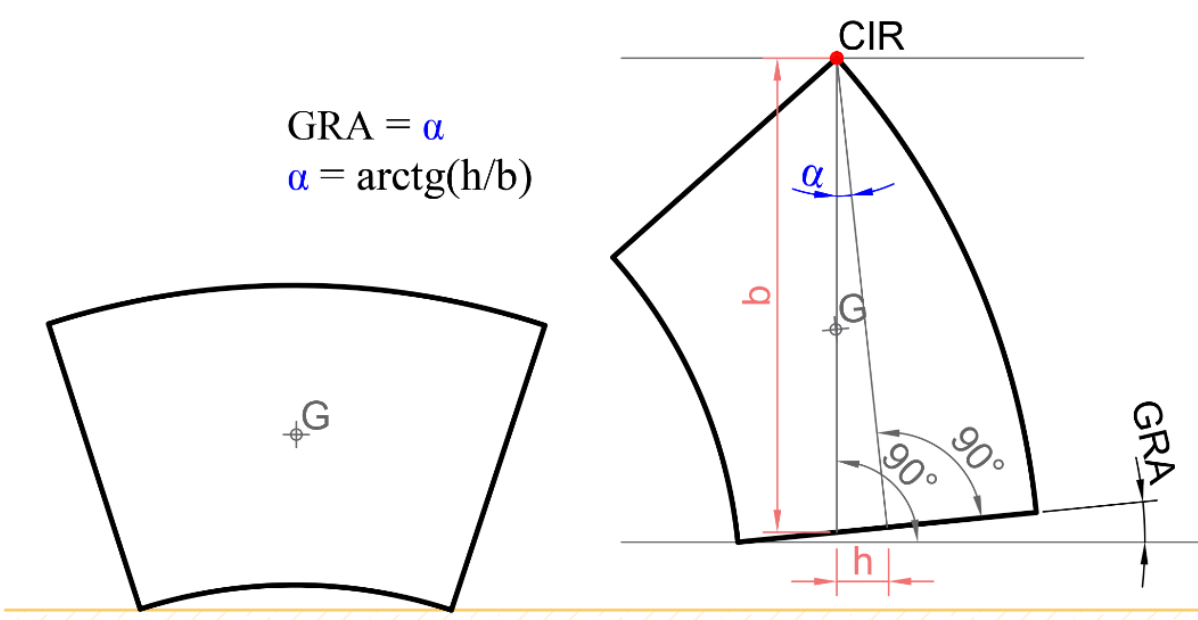

ground floor

Figure 4. Correlation between GRA and the aspect ratio of the block.

By assuming the nomenclature illustrated in Figure 5, the design procedure according to Figure 6 can be implemented. The goal is to define the optimal aspect ratio, so that all the blocks of the HLA get in contact when the arch is completely lifted. In such way, potential defects due to the positioning of the HLA are prevented. In fact, in case of the wrong aspect ratio of the blocks, especially the terminal ones, unwanted movement of the HLA can be expected during the positioning on the support-devoted structure (e.g. buttresses).

The steps for the application of the proposed model are the following:

1. Definition of the inputs. In particular, the geometry of the arched element, the mechanical characteristics of the substrate and the mechanical and geometric characteristics of the FRP material.

2. Determination of the effective bond length, $l_{e d}$, for detachment or peeling. The weight of half arch has to be considered as debonding force. 
3. Calculation of the geometric parameters, such as:

I. Impose $l_{e d}$ according to $l_{D} \geq l_{e d}$;

II. $\quad \beta=\frac{180 l_{D}}{\pi R_{e}}$;

III. $\quad l_{m}=\frac{\pi R_{m} \beta}{180}$;

IV. $\quad G R A=\operatorname{arctg}\left(\frac{h}{b}\right)$ according to Figure 4 .

4. Verification of the angles. If GRA $\leq \alpha$ the verification is satisfied, then the input geometry is valid for the purposes of the construction technique. If not, one of the following solutions should be chosen:

a. Impose $G R A_{\text {new }} \leq \alpha$ and determine $l_{m, n e w}=\operatorname{tg}(G R A)$

b. Calculate new aspect ratio by $s_{\text {new }}=\frac{l_{m}}{\operatorname{tg}(G R A)}$

c. Impose $\alpha_{\text {new }} \geq \max (\beta ; G R A)$

5. Calculation of the geometric characteristics related to the final configuration:

I. Number of blocks, $n=\frac{\pi R_{m}-\frac{\pi R_{m} \alpha}{90}}{l_{m, n e w}}$ (odd and integer number);

II. $\quad l_{m}=\frac{\pi R_{m}}{n}$;

III. $\quad \beta_{d}=\frac{180 l_{m d}}{\pi R_{e}}$;

IV. $\quad l_{D}=\frac{\pi R_{e} \beta_{d}}{180} \geq l_{e d}$.

In other words:

- Solution $a$ consists of decreasing the number of blocks.

- Solution $b$ consists of reducing the arch thickness.

- Solution $c$ consists of changing the global shape of the arch.

Combined solutions are also valid. 

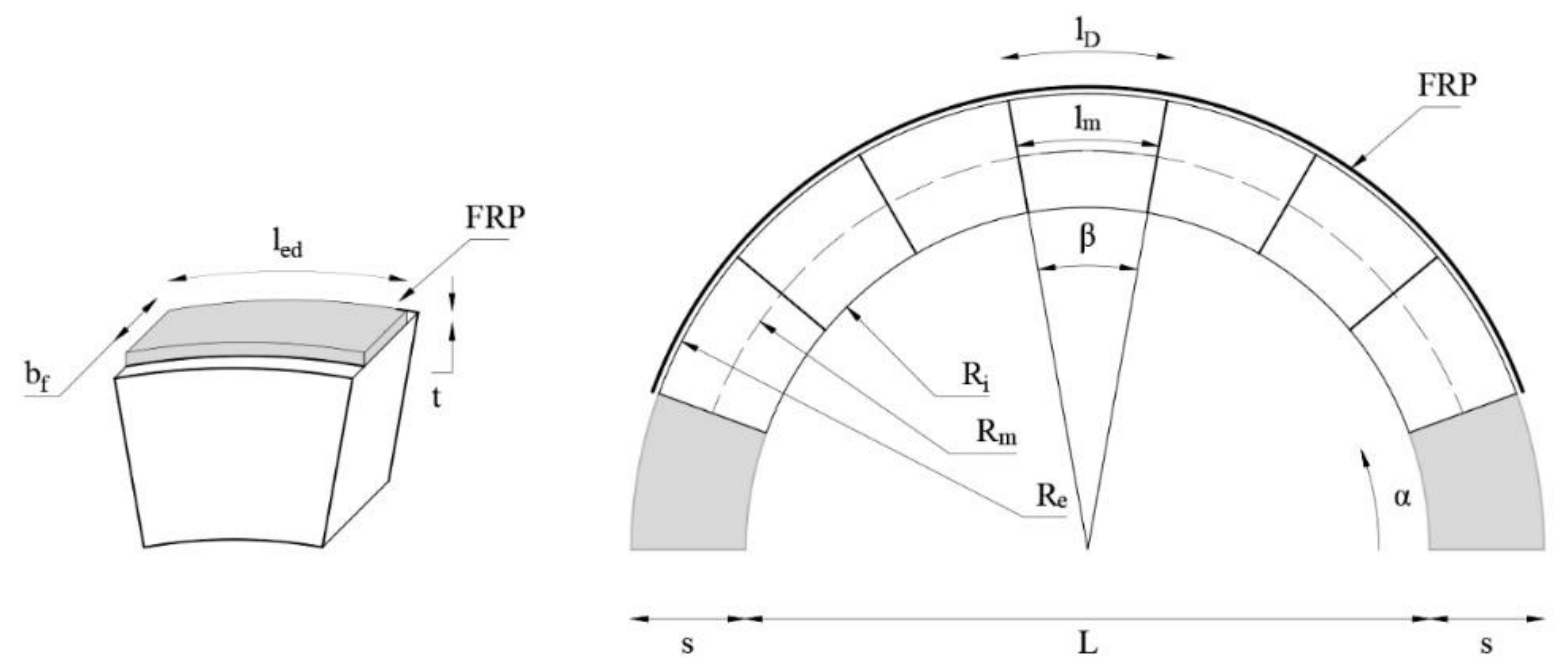

Figure 5. Nomenclature of the HLA.

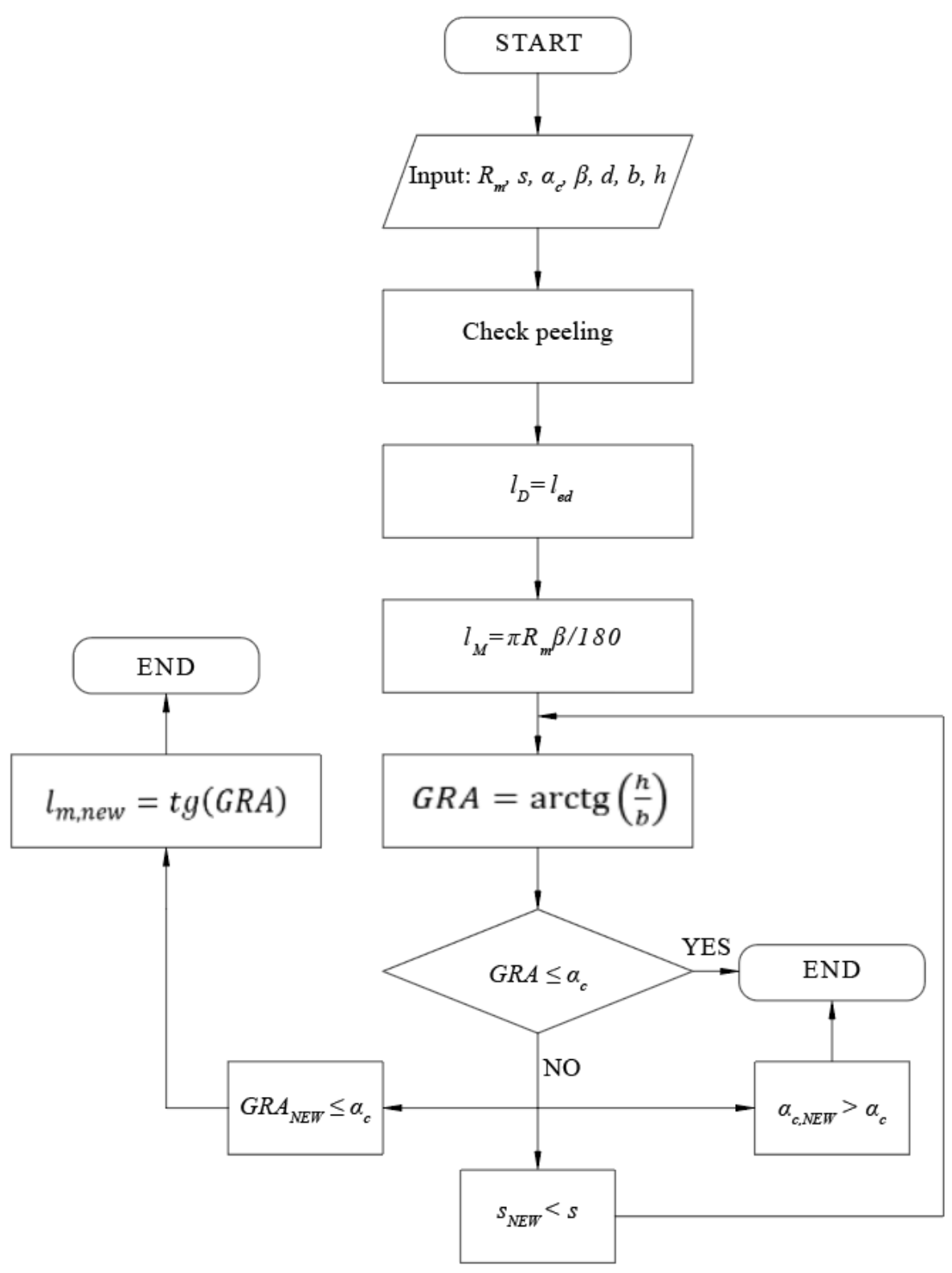

Figure 6. Flow-chart of the proposed analytical model for the design of the HLA. 


\section{Prototype}

According to the proposed model in Figure 6, $a$ combined solution between $b$ and $c$ was assumed as illustrated in Figure 7, in order to build a first experimental prototype. In fact, a total of nine blocks (I - IX) and eight hinges ( 1 - 8) were necessary in order to reach a semi-circle shape. In particular, seven blocks were identical (i.e. II - VIII) with an extrados length equal to $328 \mathrm{~mm}$ from $\alpha \geq 33^{\circ}$ (solution c); while two base blocks (I and IX) were almost double length (i.e. $657 \mathrm{~mm}$ ) according to solution $\mathrm{b}$. Both the thickness and the width of the arch were $150 \mathrm{~mm}$ and the total span was 2000 mm long.

A local stone, namely Leccese stone, with a mass density equal to $\sim 1700 \mathrm{~kg} / \mathrm{m}^{3}$ was used. The stone's compressive strength was experimentally estimated equal to $12.03 \pm 1.25 \mathrm{MPa}$ according to ASTM C170 / C170M-17. The blocks were cut by a numerical control machine so as to obtain the design curvature, once the lifting was done.

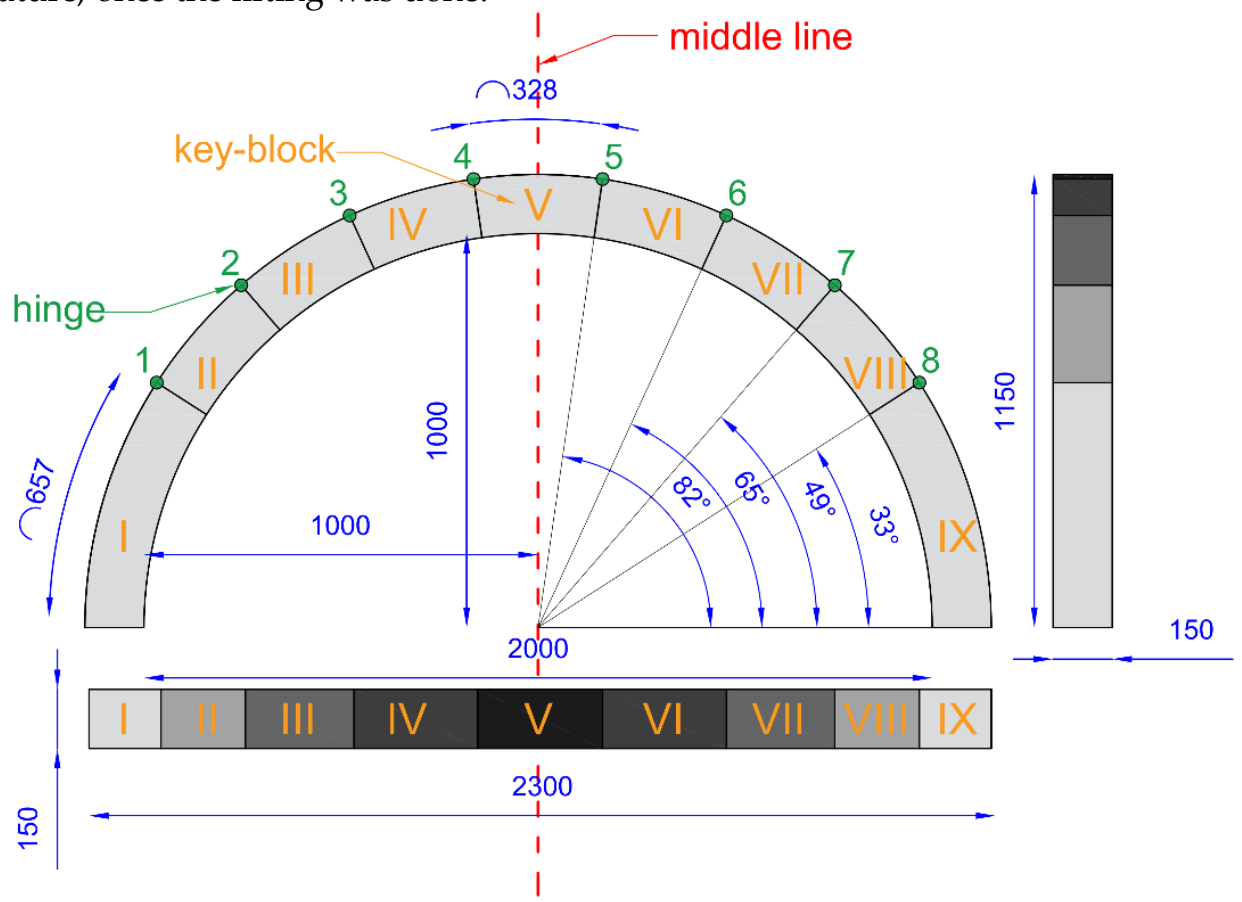

Figure 7. Prototype geometry (dimensions in $\mathrm{mm}$ ).

First, the extrados of the blocks was cleaned with compressed air to eliminate surface dust and then it was prepared with a film of epoxy primer. After that, the blocks were joined by gluing a carbon sheet $(150 \times 3600 \mathrm{~mm})$ on the extrados through an epoxy-based matrix. The main properties of the Carbon-FRP (CFRP) are reported in Table 1, as tested according to ASTM D7565 / D7565M-10 (2017). The hinge in between two side-by-side blocks was obtained by using the butyl tape (see Figure 1 left and Figure 8 ) for a length of $10 \mathrm{~mm}$ and a width of $150 \mathrm{~mm}$ (=arch width), that avoid the bond between the FRP and the substrate.

Table 1. CFRP characteristics.

\begin{tabular}{cccccc}
\hline Parameter & $\begin{array}{c}\text { Tensile } \\
\text { strength } \\
\mathbf{( G P a )}\end{array}$ & $\begin{array}{c}\text { Tensile } \\
\text { strain } \\
\mathbf{( \% )}\end{array}$ & $\begin{array}{c}\text { Young's } \\
\text { modulus } \\
\mathbf{( G P a )}\end{array}$ & $\begin{array}{c}\text { Nominal } \\
\text { thickness } \\
(\mathbf{m m})\end{array}$ & $\begin{array}{c}\text { Nominal mass } \\
\text { density } \\
\left(\mathbf{g} / \mathbf{c m}^{3}\right)\end{array}$ \\
\hline Mean & 2721.06 & 1.28 & 210.89 & & \\
Median & 3072.40 & 1.34 & 209.76 & $0.165^{*}$ & $1.82^{*}$ \\
Standard Deviator & 668.80 & 0.22 & 23.75 & & \\
Coefficient of Variation & 0.25 & 0.17 & 0.11 & & \\
\hline
\end{tabular}

* data from technical sheet. 

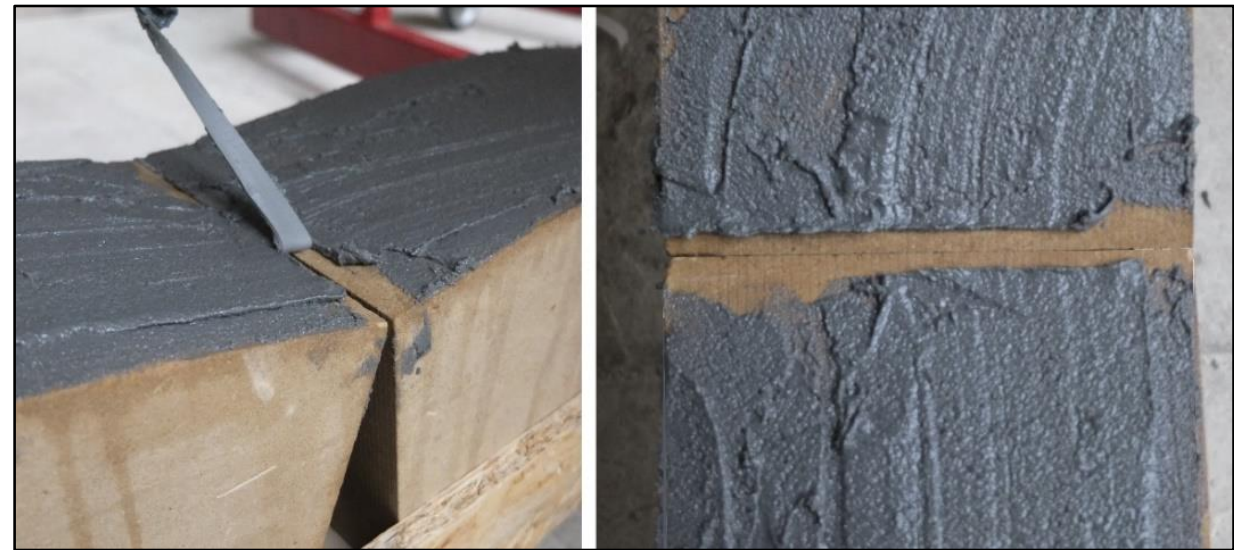

Figure 8. Detail of the hinge achievement.

\section{Test setup and instrumentation}

The prototype was instrumented and the measuring tools are illustrated in Figure 9. A tower crane was connected to the key-block by means of a harness. The arm of the tower crane is able to rotate. A Linear Variable Differential Transformer (LVDT) was oriented perpendicularly to the arm in order to measure the rotation, which is rigidly correlated to the lifting of the key-block by linear proportion (see Figure 10). Moreover, eight strain gauges (SGs) were applied on the CFRP in proximity of the hinges (SG1 - SG8). The LVDT and the SGs were connected to a data acquisition control unit. Finally, three cameras filmed the lifting from $0^{\circ}, 45^{\circ}$ and $90^{\circ}$ orientations with respect to the normal-line of the key-block. In front of the HLA a couple of Tuff-masonry buttresses, with

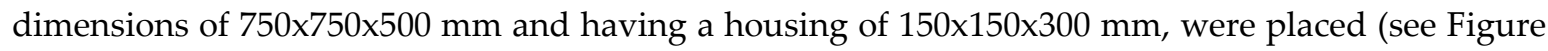
9). The lifting was manually performed by taking care that the end of the arm of the tower crane remained vertically aligned with the key-block. Four instants of the lifting procedure are illustrated in Figure $11 \mathrm{a}-\mathrm{d}$. It is evident that the hinges acting properly while allowing the rotation of the adjacent blocks, which get in contact when fully lifted. The geometry of the arch assumed the design shape when the ends blocks full-rotated. Once the lifting was completed, all the blocks were visibly in contact. In this sense, the analytical procedure reported in Figure 6 was validated. Finally, the HLA was positioned on the buttresses (see Figure 12). The obtained prototype evidenced the reliability of the proposed construction technique. The housings had the role to constrain both the horizontal displacement and the out-of-plane rotation of the arch. Further photographic evidence is reported in the Annex.

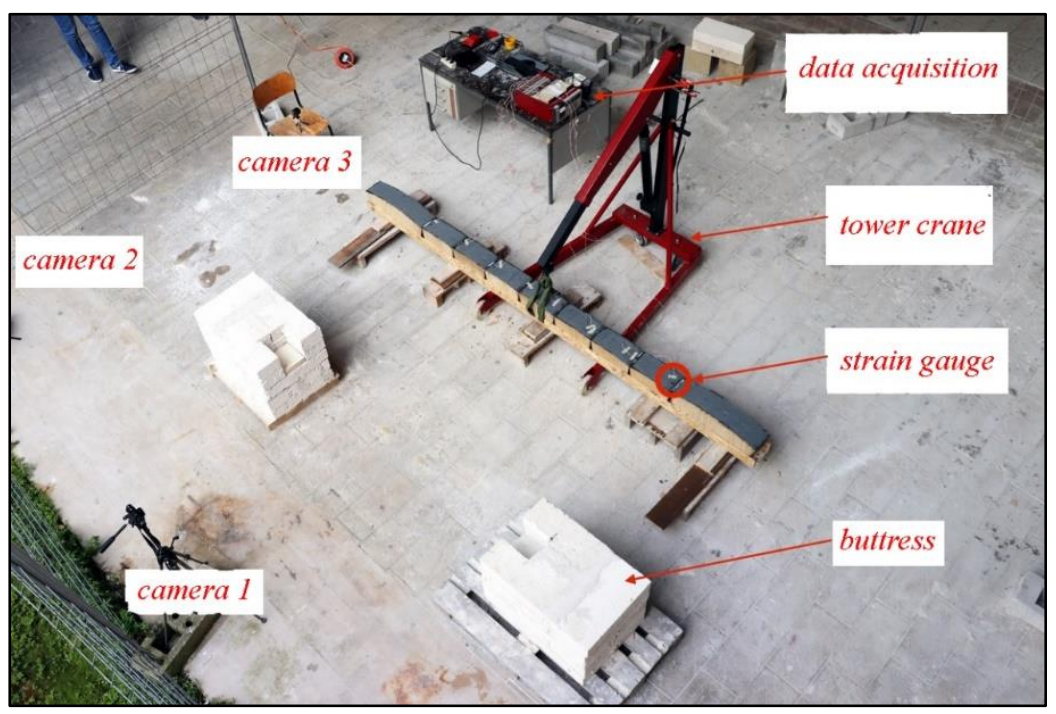

Figure 9. Prototype equipment. 


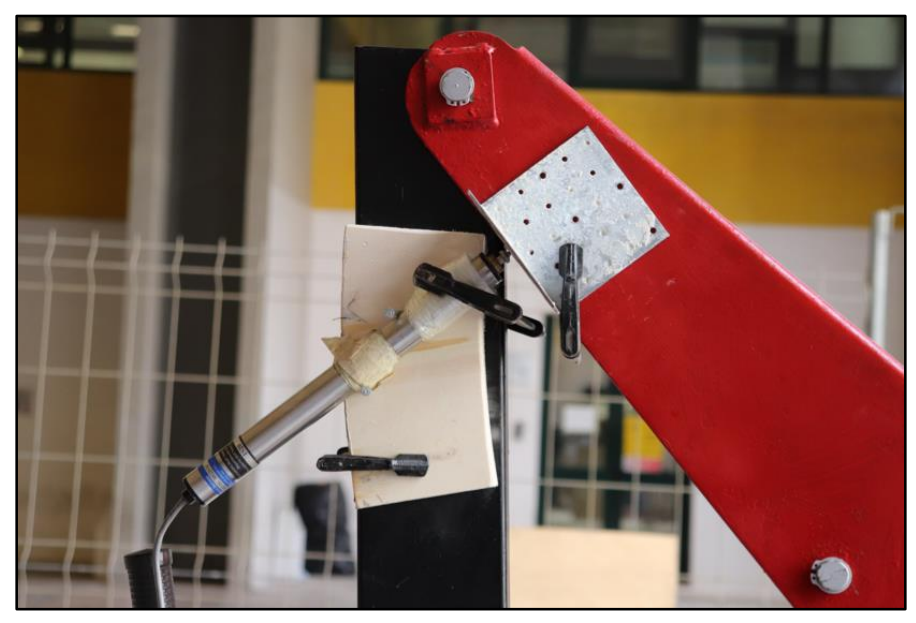

Figure 10. Detail of the LVDT installation.

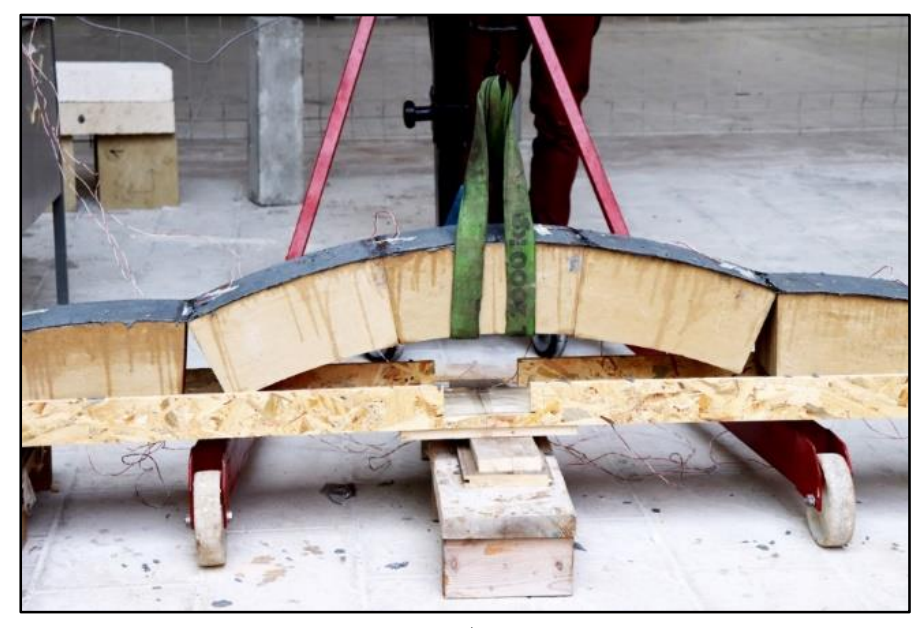

a)

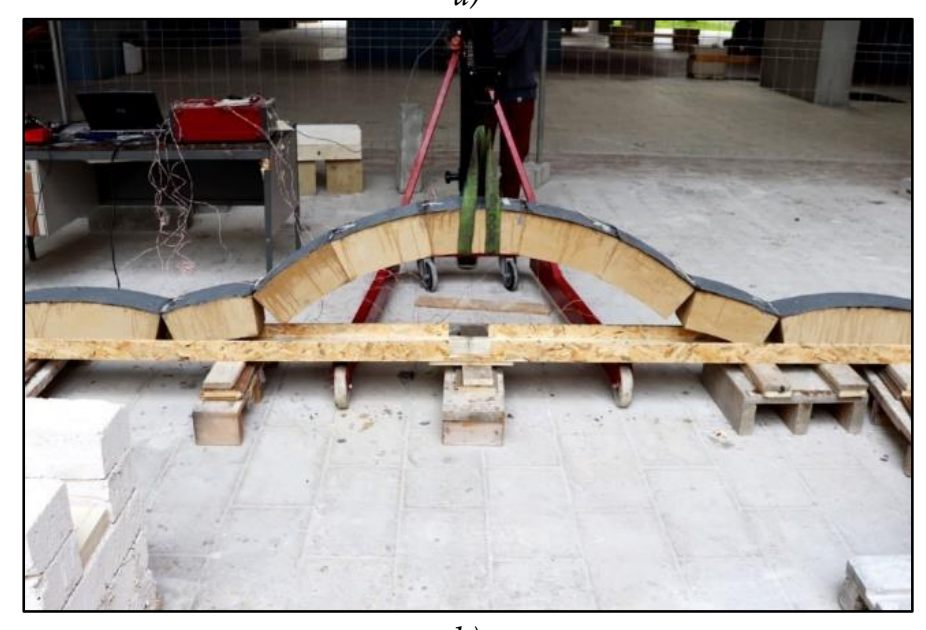

b) 


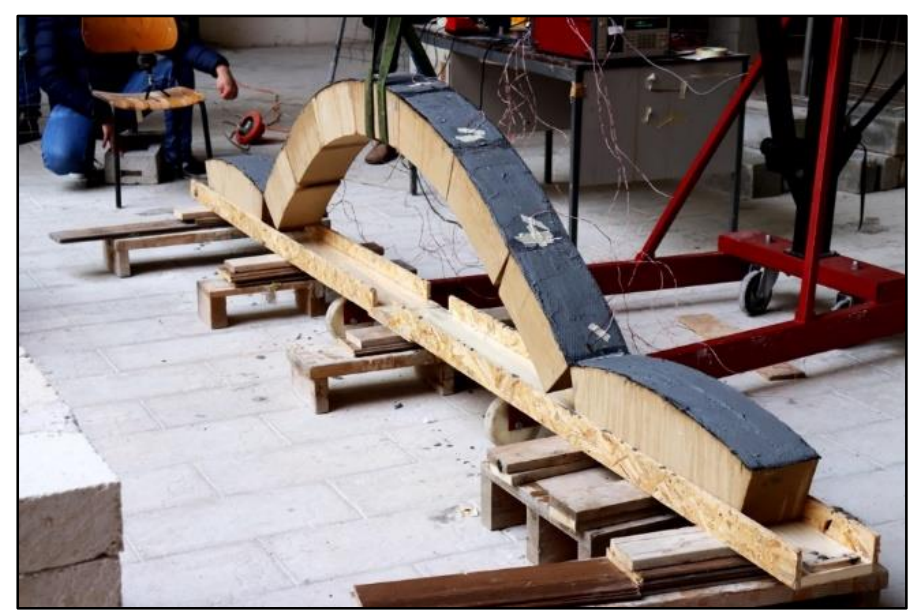

c)

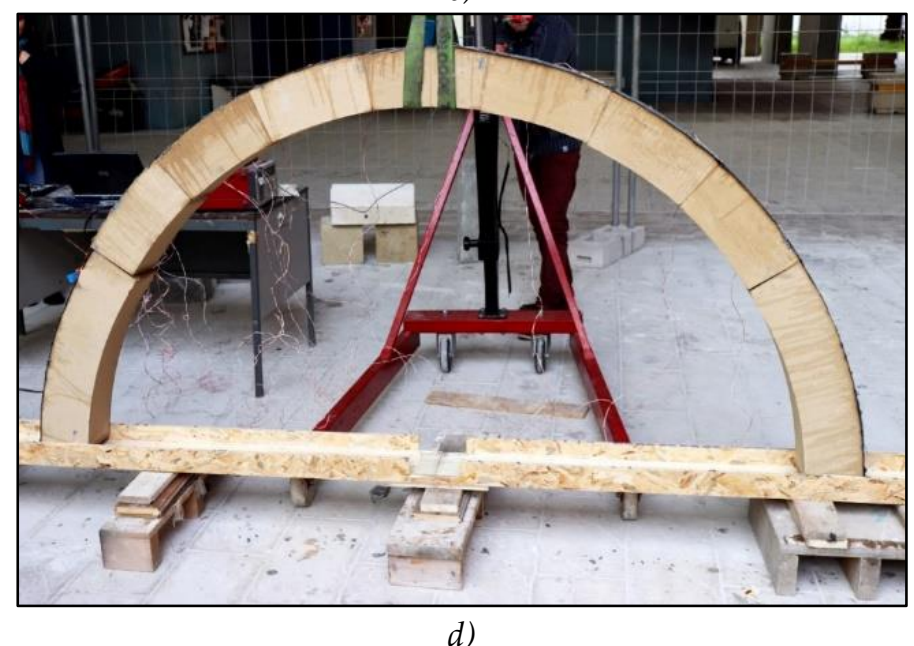

Figure 11. Progress of the lifting: from $a$ to $d$.

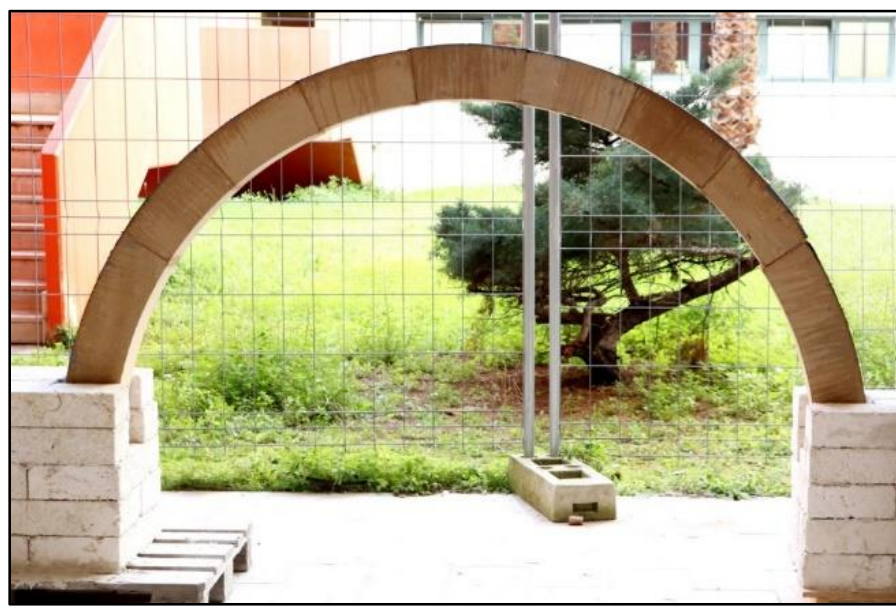

Figure 12. Placing of the HLA on the buttresses. 


\section{Discussion}

After lifting, the acquired data were processed. In particular, the FRP strains were related to the position of the SGs (see Figure 13 top), or rather to the key-block lift (see Figure 13 bottom). It can be noticed that the lifting was not symmetric; in fact, the histograms graph shows different tensile strain between left and right blocks with respect to the middle-line. This phenomenon was due to the noncorrect positioning of the harness. In the authors opinion, the issue may be solved by three points lifting (e.g. in blocks IV, V and VI).

Furthermore, the Figure 13 demonstrated that tension on the extrados of the key-block increases linearly with respect to the weight of the lifted arch. The finding confirmed the assumption reported in point 2 of section "Prototype"; in fact, the tensile strain of the key-block is not limited by the contact with the adjacent block, but depends on the weight of the whole arch. Anyway, the recordings evidenced that the tensile strain was very limited if compared with the maximum CFRP tensile strain, typically more than three/four times higher (see Table 1).
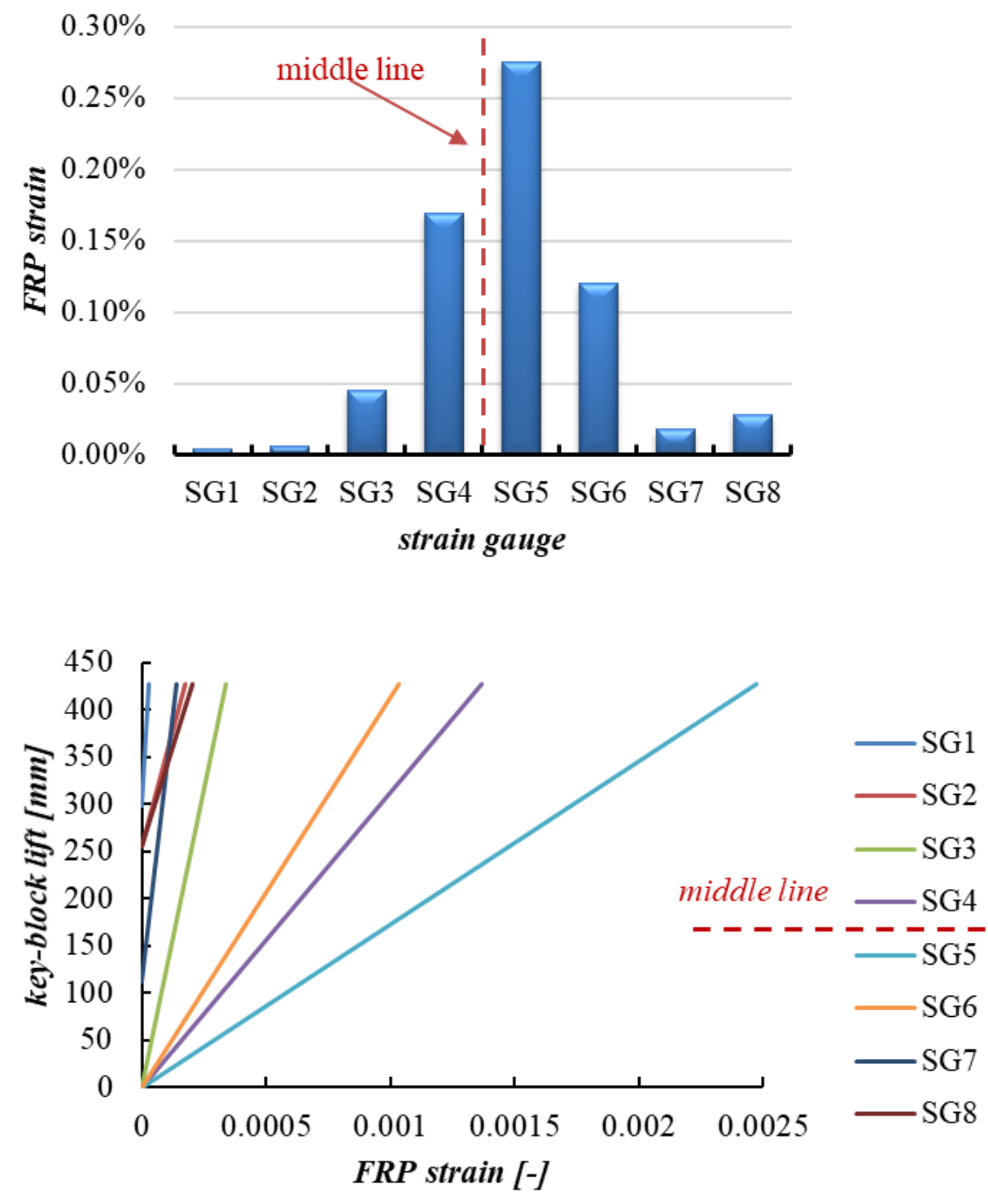

Figure 13. Placing of the HLA on the buttresses. 


\section{Conclusions}

The present paper presented a new constructive technology for curved masonry elements, by using externally bonded FRP materials instead of traditional temporary scaffolds (namely centina). A calculation model for the design of the proposed technique was developed and illustrated. Furthermore, an experimental prototype was built by using limestone blocks. As a consequence of the obtained results, the following conclusions are reported in order to highlight the advantages of the proposed technique:

- possibility of building arches in-situ by using FRP materials and lifting techniques, avoiding the use of traditional method, such as temporary scaffolding;

- the proposed construction technology has several advantages in terms of construction timesaving, ease of installation, safety, lower construction site costs and the possibility of constructing masonry arches even at high altitudes. In addition to this the seismic capacity of the arch is increased thanks to the presence of the FRP;

- the calculation model for the design of the construction technique has the advantage of being able to be applied to any curved structure;

- the experimental prototype confirmed the validity of the analytical procedure and the fast and cheap application of the technique.

In this perspective, possible future research developments are proposed, such as:

- further optimizations regarding the construction and installation of arches using the lifting technique, with particular attention to materials and tools to be used;

- application of the technique also to curved glulam timber structures;

- application to 3D structures like vault and dome;

- development of software applications for the design;

- mechanical testing under different load conditions, as typically done for FRP-strengthened masonry arches (in progress).

\section{Patents}

Cascardi, A., Micelli, F., and Aiello, M. A. (2018). “Italian Patent application No 102018000006801 - Metodo di costruzione e progettazione per la realizzazione di un'opera curva autoportante comprendente una pluralità di blocchi attigui." Italy.

Author Contributions: Conceptualization, A.C. and F.M.; methodology, F.M.; validation, M.A.A.; formal analysis, A.C.; investigation, A.C., F.M. and M.A.A.; resources, F.M.; data curation, A.C.; writing-original draft preparation, A.C.; writing-review and editing, F.M. and M.A.A.; visualization, M.A.A.; supervision, M.A.A.; project administration, A.C.; funding acquisition, F.M. All authors have read and agreed to the published version of the manuscript.

Conflicts of Interest: The authors declare no conflict of interest 
Appendix A

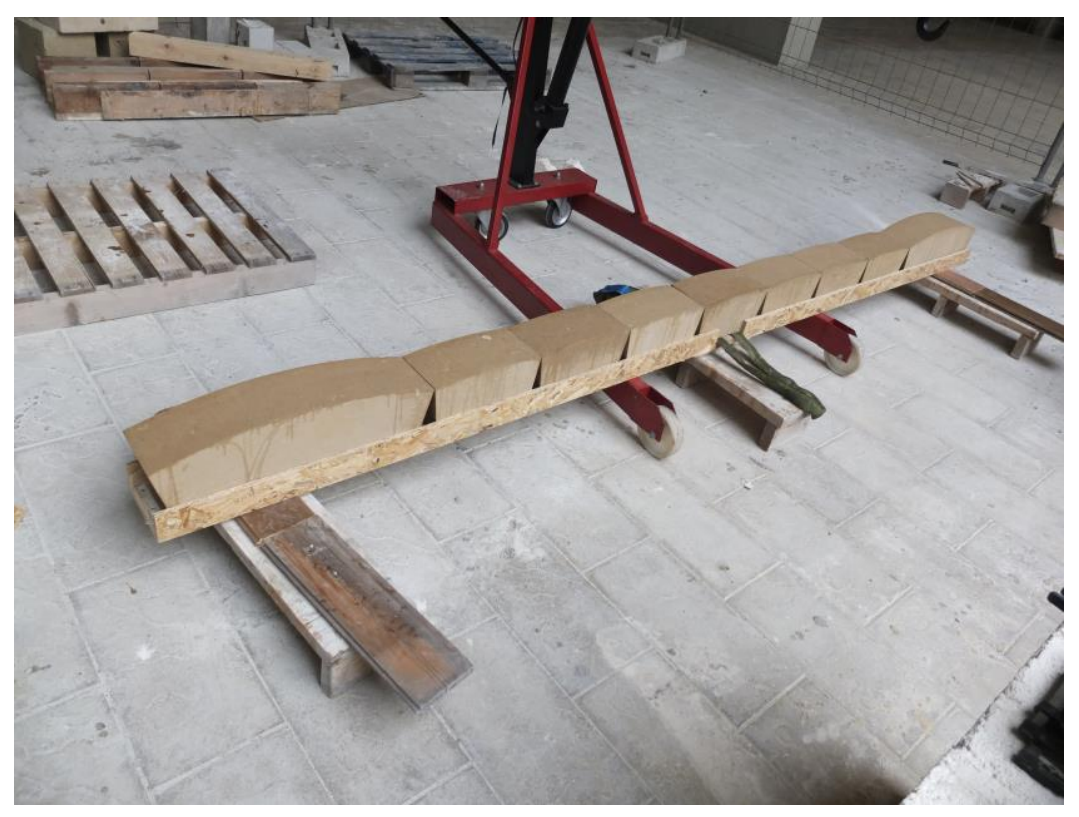

Blocks placing.

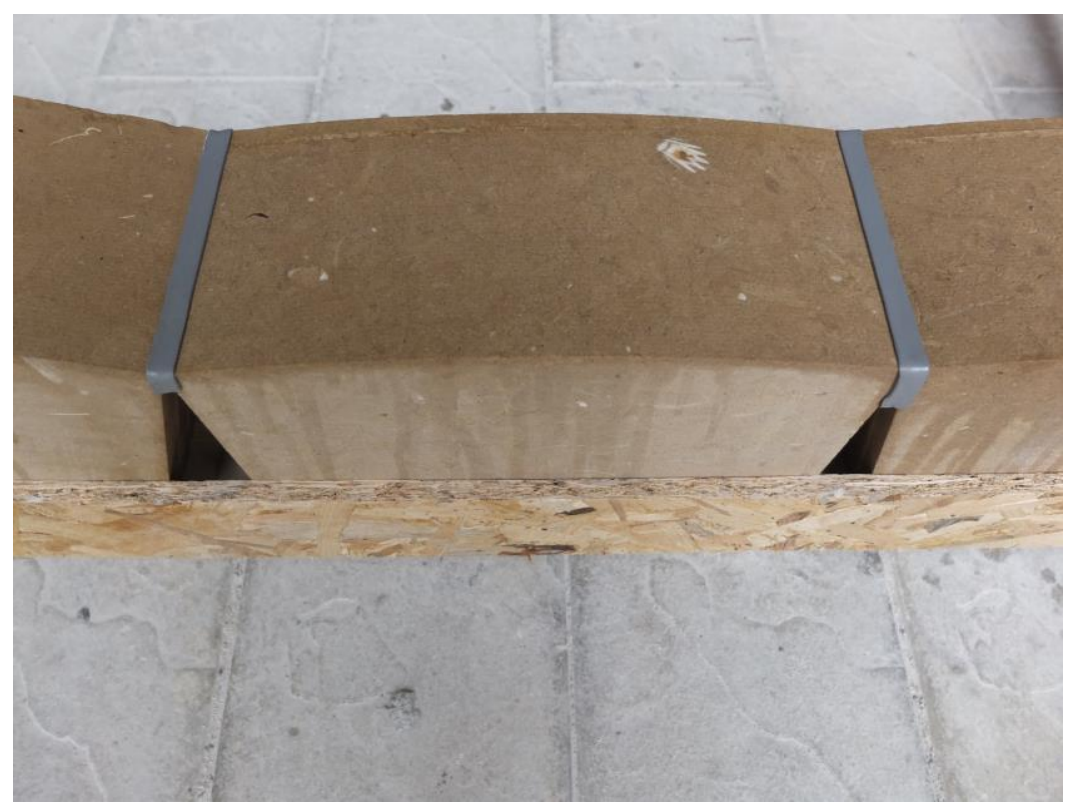

Detail of the butyl tape. 


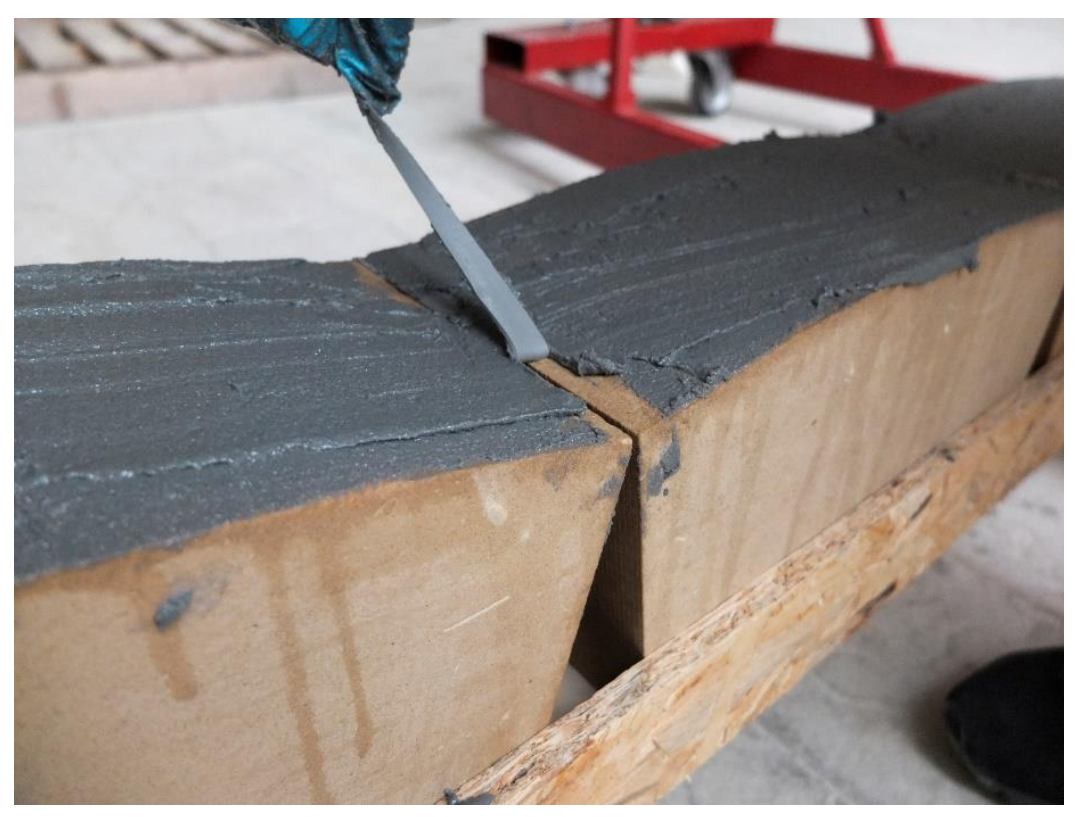

Butyl tape removing.

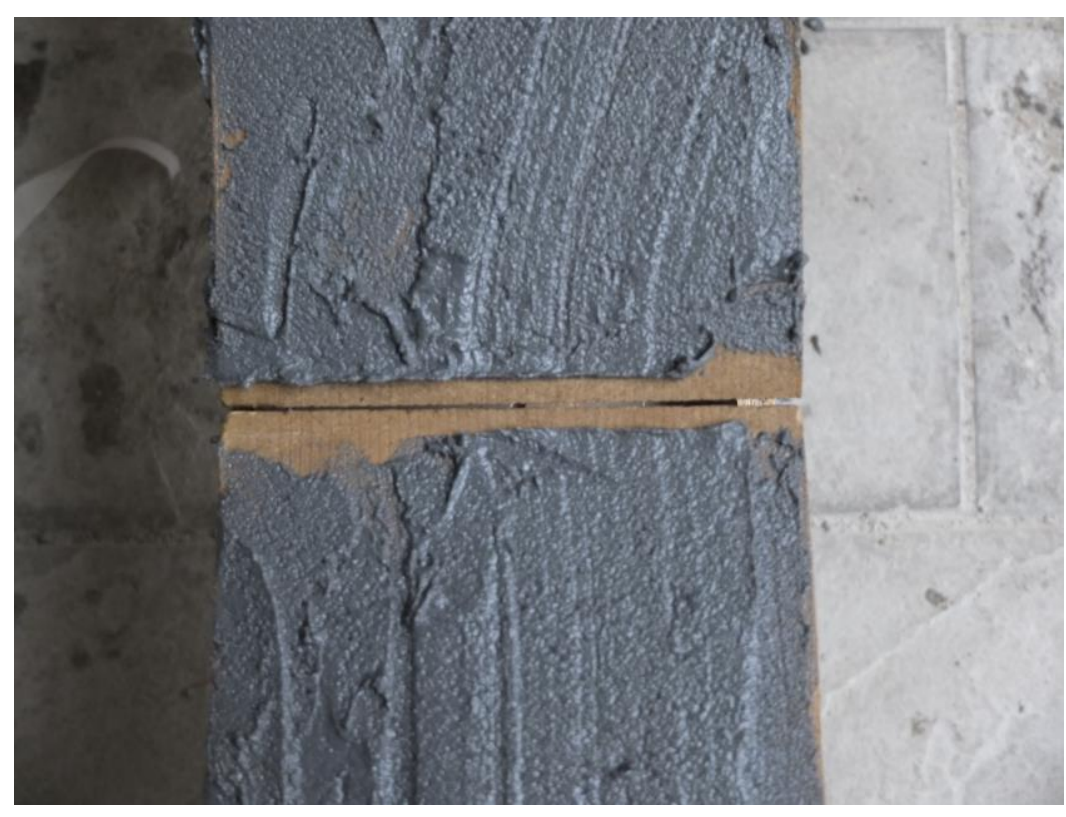

Detail of the free resin line. 


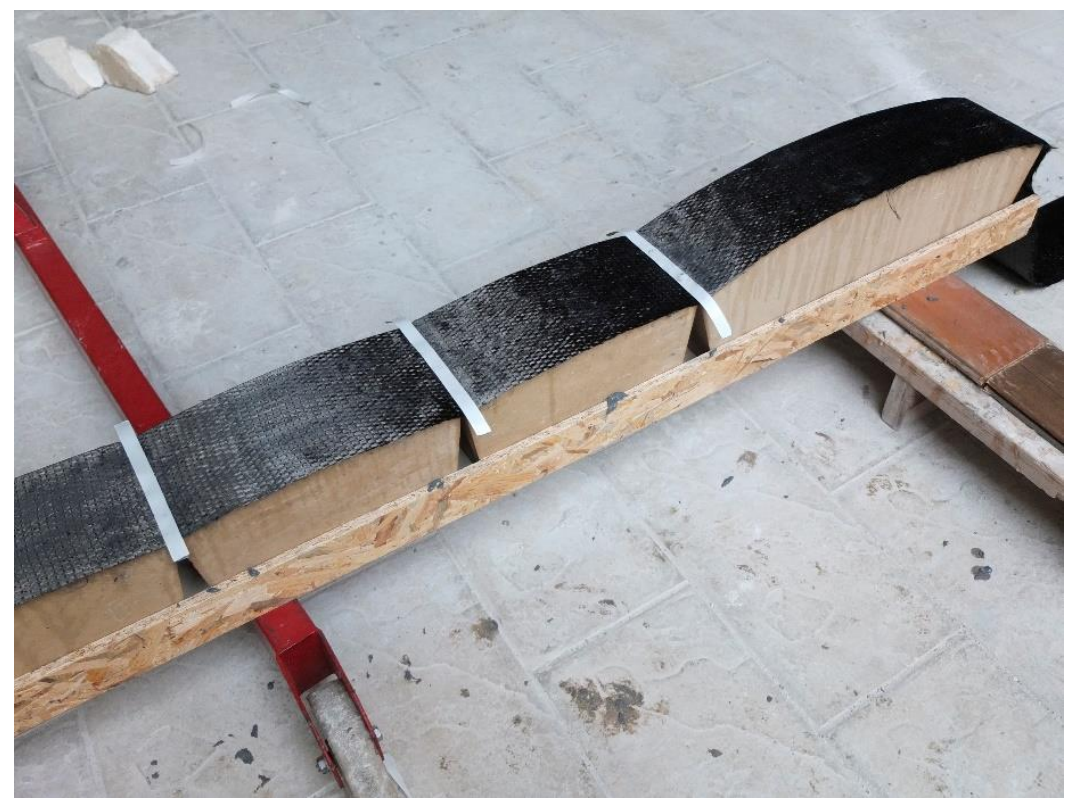

Butyl tape above the carbon fiber sheet.

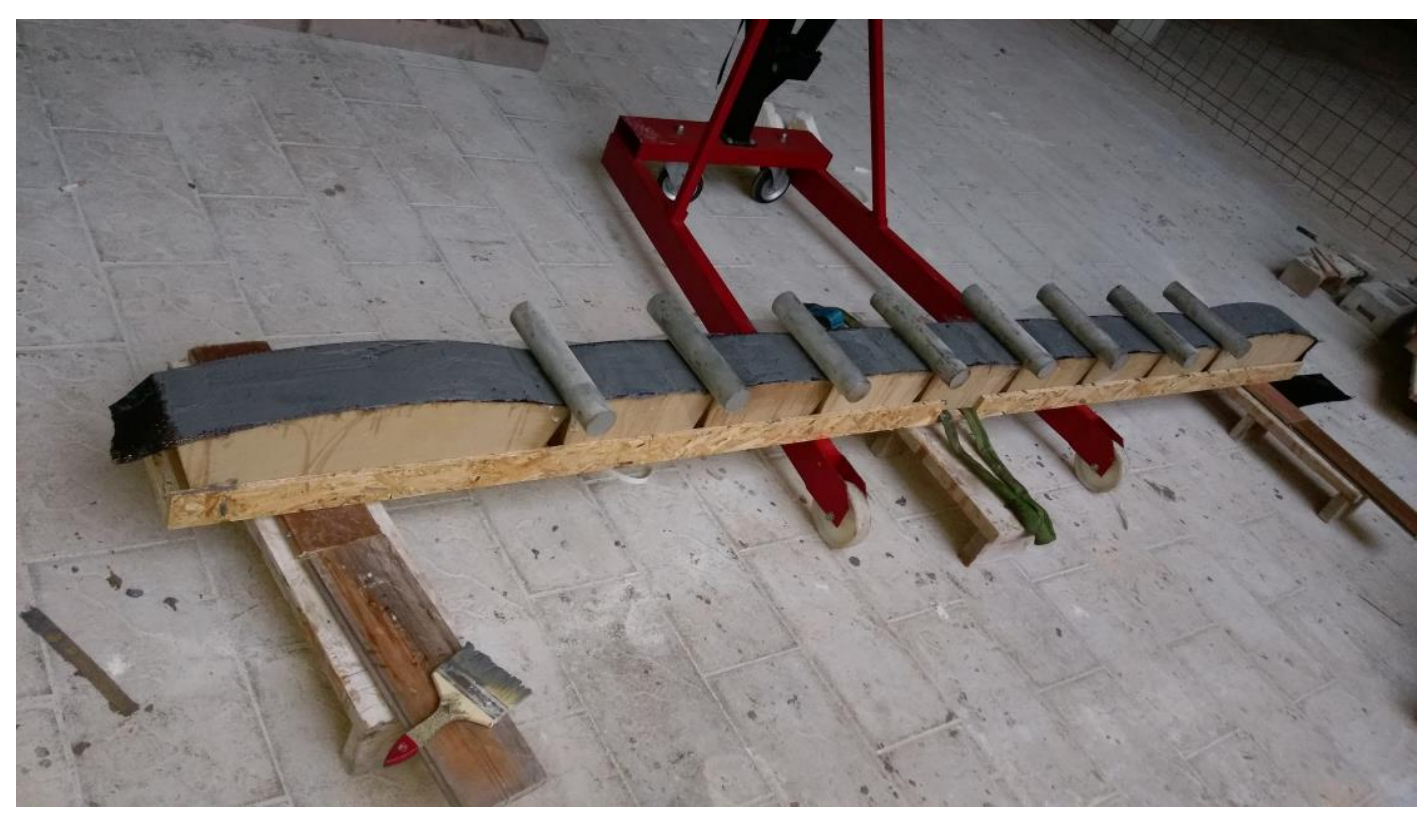

Steel cylinders weighing on the butyl tape. 


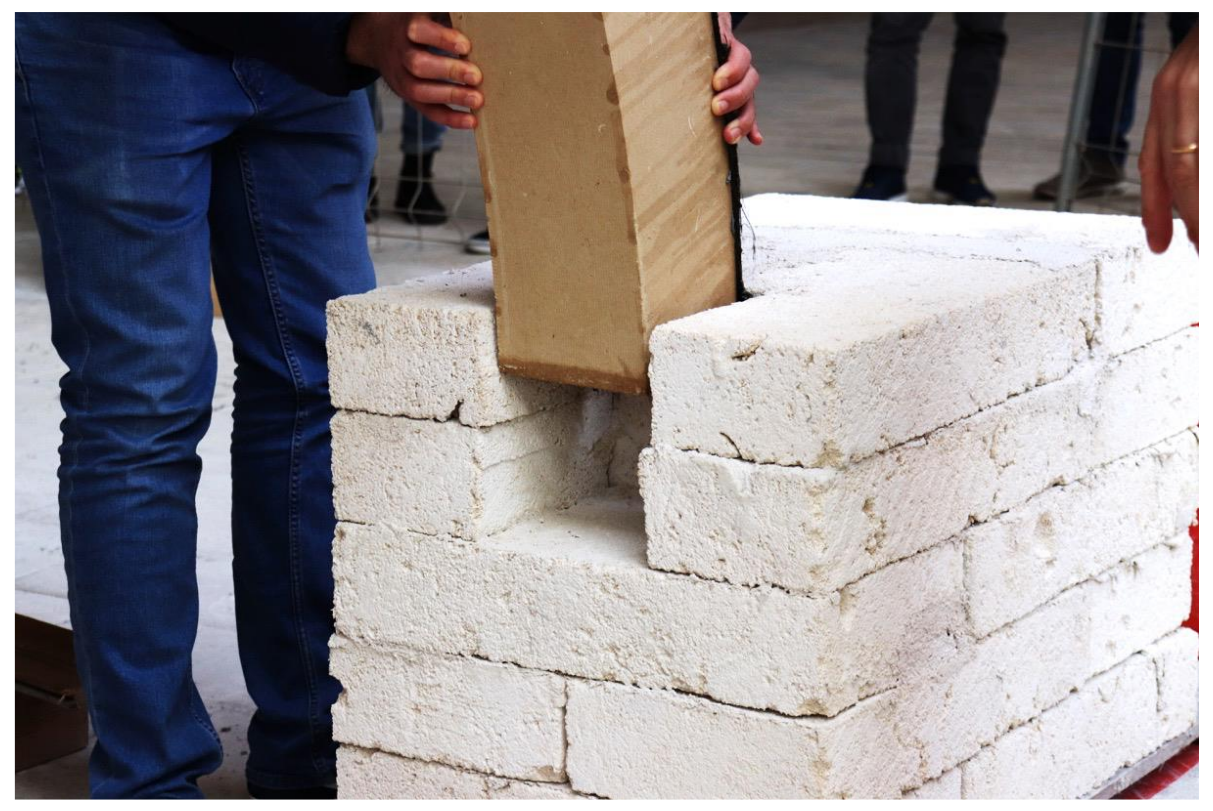

Positioning on the buttress.

\section{References}

1. Collins, R. (1968). “The Transfer of Thin Masonry Vaulting from Spain to America." Journal of the Society of Architectural Historians, 27(3), 176-201.

2. Neumann, D. (1999). "The Guastavino System in Context: History and Dissemination of a Revolutionary Vaulting Method." APT Bulletin, 30(4), 7-13.

3. Ramage, M., and Kent, B. (2007). "Guastavino 's Vault Construction Revisited." Construction History Society, 22, 47-60.

4. Rota, M., Pecker, A., Bolognini, D., and Pinho, R. (2015). “A methodology for seismic vulnerability of masonry arch." Journal of Earthquake Engineering, 37-41.

5. Zampieri, P., Zanini, M. A., and Modena, C. (2015). "Simplified seismic assessment of multi-span masonry arch bridges." Bulletin of Earthquake Engineering, Springer Netherlands, 2629-2646.

6. Cascardi, A., Micelli, F., and Aiello, M. A. (2018). "Italian Patent application No 102018000006801 - Metodo di costruzione e progettazione per la realizzazione di un'opera curva autoportante comprendente una pluralità di blocchi attigui." Italy.

7. Heyman, J. (1966). “The stone skeleton.” International Journal of solids and structures, 2(2), 249-279.

8. Heyman, J. (1982). The masonry arch. (Chichester: Horwood, ed.).

9. Oliveira, D. V, Ph, D., Basilio, I., Ph, D., Lourenço, P. B., and Ph, D. (2010). "Experimental Behavior of FRP Strengthened Masonry Arches." Journal of Composites for Construction, 5(3), 312-322.

10. Valluzzi, M., Valdemarca, M., and Modena, C. (2001). "Behavior of brick masonry vaults strengthened by FRP laminates." Journal of Composites for Construction, 5(3), 163-169. 